\title{
Estado e embates socioterritoriais na Bolívia do século XXI
}

\section{HOYÊDO NUNES LINS*}

State and social territorial conflicts in Bolivia in the 21 st century. Recent results of presidential elections in Latin America suggest a turn to the left in various countries. In Bolivia, such a movement includes the victory of an Aymara Indian who is also a leader of coca farmers. The article proposes an interpretation of this event, describes and discusses the main actions of the new government, stressing the reactions they provoked, and explores the class, ethnic and territorial dimensions of the resulting conflicts. The regional aspects of the fights, seen in connection with the country's historical regionalism, are highlighted and their basic conditions are investigated.

Keywords: Bolivia; Morales government; social fights; regionalism

JEL Classification: H70; O54; R50

\section{INTRODUÇÃO}

A América Latina tem frequentado as manchetes internacionais com assiduidade nos últimos anos. Entre os principais motivos, figura a sucessão de eventos que, em vários países, entronizaram ou mantiveram governantes que acenavam com transformações. Nesse processo, cabe realçar a experiência da Bolívia, pela incrustada simbologia e a aparente inflexão numa trajetória multissecular: por conta de resultado eleitoral inédito, tomou posse como Presidente da República em janeiro de 2006 um indígena aimará líder de plantadores de coca.

O primeiro ano do governo de Evo Morales foi marcado por medidas de grande repercussão nos planos externo e interno. A nacionalização do setor de hidro-

\footnotetext{
* Professor do Departamento de Ciências Econômicas e do Programa de Pós-Graduação em Economia da Universidade Federal de Santa Catarina. E-mail: hnlins@cse.ufsc.br. Submetido: Julho 2007; Aprovado: Outubro 2007.
} 
carbonetos canalizou as atenções, mas tal iniciativa integra leque maior de ações destinadas a mudar profundamente um país situado entre os mais pobres e desiguais de toda a América Latina. Assim, essas providências reverberaram sobretudo no front interno, suscitando embates estridentes e de conteúdo étnico, de classe e territorial, apresentando-se o último aspecto estreitamente vinculado à diferenciação socioespacial que caracteriza o país e que sobressai nos fatores que fazem do regionalismo um traço histórico da vida boliviana. Regionalismo, assinale-se, é termo que aqui refere à "reivindicação política de um grupo de pessoas identificado territorialmente contra um ou muitos mecanismos do Estado" (Markusen, 1981: 83).

As implicações domésticas das ações do novo governo da Bolívia constituem o objeto deste artigo. Mas também se pretende, além de abordá-las, contextualizar a vitória eleitoral de Evo Morales e interpretar as reações às medidas governamentais. O passo inicial consiste em reconhecer o cenário desse processo; depois sistematizam-se os acontecimentos que levaram à aludida vitória, descrevem-se as iniciativas do governo, com as reações provocadas, explora-se a dimensão socioespacial dos decorrentes embates e apresentam-se os vetores da atual questão regional na Bolívia.

\section{PERFIL DA SOCIOECONOMIA BOLIVIANA NA AURORA DO SÉCULO XXI}

A Bolívia tem cerca de 9 milhões de habitantes, na maioria instalados em áreas urbanas. Suas cidades com população superior a um milhão, Santa Cruz de la Sierra (capital do Departamento de Santa Cruz) e La Paz (capital administrativa do país), concentravam 31\% dos bolivianos em 2004 (World..., 2006). Nas áreas rurais (principalmente nas regiões central e altiplânica) vive boa parte dos estratos ameríndios, que somam mais da metade da população total e exibem o quíchua e o aimará, descendentes dos incas, como grupos principais.

O PIB boliviano mostrou-se pouco inferior a US\$ 8,8 bilhões em 2004, com o setor de serviços participando com mais da metade, a agricultura com apenas $16 \%$ e a indústria de transformação (geralmente atividades tradicionais e de pequena escala) com meros $14 \%$. Mas a indústria como um todo alcançou $31 \%$, refletindo o peso da mineração (destacando-se o estanho), do petróleo (extração e refino) e do gás, os quais, acompanhados da agroindústria, respondem pelo essencial das exportações, endereçadas sobretudo para Brasil, Colômbia e Estados Unidos. O quadro produtivo ganha mais nitidez com dados sobre importações: naquele ano, eloquentes $79 \%$ vincularam-se a produtos manufaturados; nas últimas décadas, Argentina, Estados Unidos e Brasil alternam-se como principais origens.

Sobre a situação social, cabe assinalar que $23,2 \%$ e $42,2 \%$ da população viviam com menos de, respectivamente, US\$ 1,00 e US\$2,00 por dia em 2002, sendo as mesmas percentagens para toda a América Latina e o Caribe iguais a 8,9\% 
e 23,4\% (World Development Indicators, 2006). O Índice de Desenvolvimento Humano (IDH) era de 0,641 em 2001, e, em 2005, o lugar da Bolívia entre 177 países era o $113^{\circ}$, à frente apenas, na América Latina e no Caribe, de Honduras, Guatemala e Haiti (Human..., 2005). A Tabela 1 informa sobre esses aspectos.

Tabela 1 - Bolívia: indicadores socioeconômicos selecionados

\begin{tabular}{|c|c|c|}
\hline & Indicadores & Números \\
\hline $\begin{array}{l}\text { Aspectos } \\
\text { Populacionais }\end{array}$ & $\begin{array}{l}\text { POPULAção TOTAL (2004) } \\
\text { Taxa média anual de crescimento da população total (1990-2004) } \\
\text { População rural (2004) } \\
\text { Taxa média anual de crescimento da população rural (1990-2004) } \\
\text { População urbana (2004) } \\
\text { Taxa média anual de crescimento da população urbana (1990-2004) }\end{array}$ & $\begin{array}{r}9,0 \text { milhões } \\
2,1 \% \\
3,2 \text { milhões } \\
0,7 \% \\
5,8 \text { milhões } \\
3,1 \%\end{array}$ \\
\hline $\begin{array}{l}\text { Aspectos Étnicos } \\
\text { (primeira metade } \\
\text { dos anos 2000) }\end{array}$ & 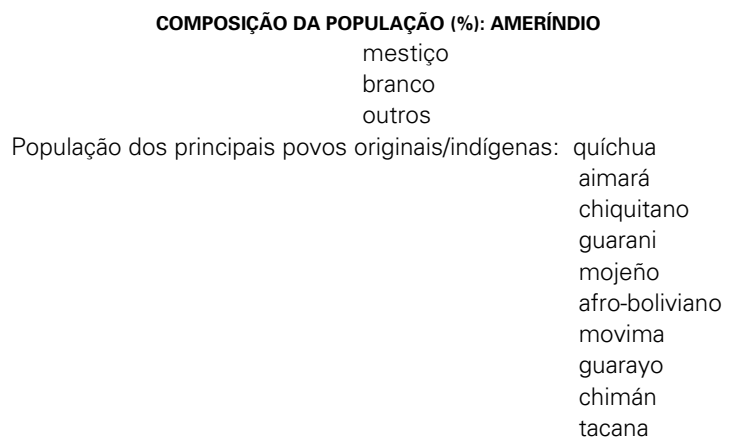 & $\begin{array}{r}55 \% \\
27,5 \% \\
15 \% \\
2,5 \% \\
2.558,3 \mathrm{mil} \\
2.098,3 \mathrm{mil} \\
184,3 \mathrm{mil} \\
133,4 \mathrm{mil} \\
76,1 \mathrm{mil} \\
22,0 \mathrm{mil} \\
10,2 \mathrm{mil} \\
9,9 \mathrm{mil} \\
8,5 \mathrm{mil} \\
7,1 \mathrm{mil}\end{array}$ \\
\hline $\begin{array}{l}\text { Produto Interno } \\
\text { Bruto (2004) }\end{array}$ & $\begin{array}{l}\text { Valor } \\
\begin{array}{ll}\text { Composição (\%): } & \text { agricultura } \\
& \text { indústria } \\
& \text { indústria de transformação } \\
& \text { serviços }\end{array}\end{array}$ & $\begin{array}{r}\text { US\$ } 8.773 \\
\text { milhões } \\
16 \% \\
31 \% \\
14 \% \\
54 \% \\
\end{array}$ \\
\hline $\begin{array}{l}\text { Comércio Exterior } \\
(2004)\end{array}$ & $\begin{array}{l}\text { Valor das exportações } \\
\text { Composição das exportações (\%): } \begin{array}{l}\text { alimentos } \\
\text { matérias-primas agrícolas } \\
\text { combustíveis } \\
\text { minérios e metais } \\
\text { produtos manufaturados } \\
\text { Valor das importações } \\
\text { Composição das importações (\%): } \\
\text { alimentos } \\
\text { matérias-primas agrícolas } \\
\text { combustíveis } \\
\text { minérios e metais } \\
\text { produtos manufaturados }\end{array}\end{array}$ & $\begin{array}{r}\text { US\$ } 2.129 \\
\text { milhões } \\
27 \% \\
2 \% \\
38 \% \\
19 \% \\
14 \% \\
\text { US\$ } 1.842 \\
\text { milhões } \\
12 \% \\
2 \% \\
7 \% \\
1 \% \\
79 \%\end{array}$ \\
\hline $\begin{array}{l}\text { Pobreza } \\
(2002)\end{array}$ & $\begin{array}{l}\text { População vivendo com menos de US\$1,00 por dia (\%) } \\
\text { População vivendo com menos de US\$2,00 por dia (\%) }\end{array}$ & $\begin{array}{l}23,2 \% \\
42,2 \%\end{array}$ \\
\hline $\begin{array}{l}\text { Índice de Desenv. } \\
\text { Humano }\end{array}$ & $\begin{array}{l}\text { IDH (2001) } \\
\text { Posição no ranking do IDH em conjunto de } 177 \text { países (2005) }\end{array}$ & $\begin{array}{r}0,641 \\
113^{\circ}\end{array}$ \\
\hline
\end{tabular}

Fontes: Elaborado pelo autor com base em: World Development Indicators, 2006 para Aspectos Populacionais, PIB, Comércio Exterior e Pobreza; Pinto (2006) para Aspectos Étnicos; Índice... (2004) para IDH em 2001; Human... (2005) para ranking do IDH em 2005. 
Entretanto, o território nacional é heterogêneo em termos socioeconômicos. Em 2003, mais de 70\% da população se concentrava em três dos seus nove departamentos: La Paz, Santa Cruz e Cochabamba (Tabela 2). Esses departamentos são os que mais participam no PIB boliviano (somando quase $3 / 4$ do total), o valor do mais alto (Santa Cruz, com US\$2,5 bilhões) superando em 35 vezes o do mais baixo (Pando, com US\$ 70,3 milhões). Quanto ao PIB per capita, a diferença entre as situações extremas era de 2,8 vezes, opondo Tarija, com o mais alto, a Potosí, com o mais baixo. Essa situação se reproduz no IDH, conforme dados para 2001: Potosí, seguido por Chuquisaca, amarga situação muito precária; Santa Cruz, Tarija e Beni ocupam o topo da escala.

Tabela 2 - Bolívia: população, PIB e Índice de

Desenvolvimento Humano por Departamento

\begin{tabular}{ccccc}
\hline Departamentos & $\begin{array}{c}\text { População } \\
(\mathbf{2 0 0 3 )}\end{array}$ & $\begin{array}{c}\text { PIB em } \\
\text { US\$ mil } \\
\mathbf{( 2 0 0 3 )}\end{array}$ & $\begin{array}{c}\text { PIB per } \\
\text { capita em } \\
\text { US\$ 1,00 } \\
(\mathbf{2 0 0 3 )}\end{array}$ & $\begin{array}{c}\text { IDH } \\
(\mathbf{2 0 0 1 )}\end{array}$ \\
\hline Beni & 390.997 & 280.845 & 718 & 0,639 \\
Cochabamba & 1.596 .096 & 1.427 .637 & 894 & 0,627 \\
Chuquisaca & 581.739 & 403.004 & 693 & 0,563 \\
La Paz & 2.544 .814 & 2.038 .441 & 801 & 0,631 \\
Oruro & 425.826 & 419.021 & 984 & 0,618 \\
Pando & 60.984 & 70.321 & 1.153 & 0,624 \\
Potosí & 758.337 & 367.129 & 484 & 0,514 \\
Santa Cruz & 2.231 .019 & 2.492 .433 & 1.117 & 0,689 \\
Tarija & 434.035 & 583.721 & 1.345 & 0,641 \\
Bolívia & 9.023 .847 & 8.082 .552 & 896 & 0,641 \\
\hline
\end{tabular}

Fonte: Elaborado pelo autor com base em: Estadísticas...(2006) para População e PIB; Índice... (2004) para IDH

Em La Paz, Cochabamba, Oruro e Chuquisaca, que abrigam os maiores contingentes quíchua e aimará do país, o ambiente andino aparece em aspectos paisagísticos e climáticos que reúnem cordilheiras, vales profundos e zonas altiplânicas, com variedade de microclimas e vegetação. Isso é acompanhado por diversidade no âmbito da economia. O Departamento de La Paz desponta em atividades terciárias e também na produção de alimentos, bebidas, fumo e têxtil-vestuarista, além da mineração (notadamente zinco) e do cultivo de coca, que em 2004 representou 3/4 do valor da produção cocalera nacional. ${ }^{1}$ No Departamento de Cochabamba, os aspectos naturais se refletem no cultivo de grãos, tubérculos, frutas e hortaliças, assim como na coca, que alcançou em 2004 pouco menos de 1/4 do valor nacional;

\footnotetext{
${ }^{1}$ Os dados sobre a estrutura econômica dos departamentos foram obtidos em Estadísticas... (2006).
} 
a indústria de transformação atinge quase $25 \%$ do respectivo produto nacional, destacando-se o refino de petróleo e a produção alimentar. Em Oruro, Potosí e Chuquisaca, o quadro é distinto: nos primeiros reina a extração mineral, Oruro sobretudo com zinco e estanho (quase $3 / 4$ da produção total de estanho em 2004) e Potosí, com zinco (quase $60 \%$ da produção nacional). Em Chuquisaca, o setor primário é a base da estrutura produtiva, beneficiado por vales de clima temperado e, no leste, por zonas mais quentes e planas.

Pando, Beni, Santa Cruz e Tarija compõem grupo ainda mais diversificado. Nos dois primeiros as terras são geralmente baixas e os climas são o tropical e o tropical úmido, observando-se (em Beni) grandes planícies com pastagens e áreas de selva próprias da Bacia Amazônica. Santa Cruz e Tarija apresentam marcada variedade fisiográfica e climática, com ambientes subandinos, vales e, a leste e nordeste, vastas planícies, o todo implicando diferentes altitudes e patamares de temperatura. Esses quatro departamentos concentram populações indígenas das etnias chiquitano, guarani e mojeño, entre outras, as mais numerosas depois das de origem inca. Assinalese que os imigrantes europeus e de outras procedências que se dirigiram à Bolívia durante o século XX fixaram-se principalmente em Santa Cruz e Tarija.

Em termos econômicos, Santa Cruz e Tarija ocupam posição de absoluta proeminência. Em Tarija, o substrato é principalmente o binômio petróleo-gás natural, embora a indústria de alimentos, a agricultura e a pecuária bovina mereçam referência. É Santa Cruz, todavia, que cintila mais forte, como denota a recorrente magnitude dos números exibidos: o resultado das suas atividades do setor primário representou $43 \%$ do respectivo PIB nacional em 2004 - destacando-se produtos agrícolas industriais (soja, cana-de-açúcar) e não-industriais, além da pecuária; na indústria de transformação a porcentagem superava $35 \%$, sobressaindo a produção de alimentos e o processamento de insumos primários (vinculados a um forte setor agroindustrial) e também o refino de petróleo. Normalmente superlativos, os dados não autorizam dúvida: trata-se da principal área econômica do país, tendo participado com 31\% do PIB boliviano em 2003 (Tabela 2). Pando e Beni, em contrapartida, têm pequena expressão, não representando, somados, mais de 4,5\% do PIB nacional. Suas principais atividades são as primárias (pecuária); na manufatura, Pando registra algum realce da produção têxtil-vestuarista, o mesmo valendo para a produção alimentar em Beni.

\section{CRISE, REBELIÃO E INDIGENISMO}

A eleição de Evo Morales é indissociável dessa estrutura socioespacial crivada de desigualdades. Todavia, o abismo social e as clivagens espaciais são traços históricos desse país, sem que jamais um resultado eleitoral como o de dezembro de 2005 tenha se produzido antes. Consequentemente, o "fenômeno" Morales há de ganhar luz se observado no marco da configuração política que tomou forma na 
Bolívia nos últimos anos. Tal configuração revela, nos anos 1990 e 2000, o protagonismo de forças "nacional-populares" (a expressão remete a Zavaleta, 1986) cujo centro de gravidade é não propriamente o poder sindical ou as estruturas partidárias de esquerda, tradicionais no percurso político do país: hoje, "a grande especificidade da região andina é [...] a questão indígena" (Lipietz, 2006: s/p), pois "o indigenismo se erige em força política revolucionária" (Lipietz, 2004: s/p). Assim, mais do que guinada à esquerda, a eleição de Evo Morales consignaria uma virada "descolonial": um "giro da esquerda na América do Sul sob a liderança política, intelectual e ideológica dos movimentos indígenas [...]" (Mignolo, 2006: s/p).

Tal quadro resultou de processo marcado por revoltas populares em resposta ao turbilhão neoliberal que sacudiu a Bolívia (e a América Latina) nos anos 1980 e 1990, centrado no combate à inflação com liberalização do comércio externo, privatizações e a atração de investimentos. Os problemas estruturais do país não arrefeceram, e a multiplicação das demissões (sobretudo na mineração, agravando a pobreza no Altiplano) fez crescerem os contingentes envolvidos no cultivo de coca (Bader; Rodrigo, 1994) devido à ausência ou escassez de opções comparáveis em termos de resultados. Ao mesmo tempo, intensificou-se a repressão governamental à atividade, sob pressão dos Estados Unidos (Lemoine, 1995), desaguando em explosão de conflitos que não permite surpresa com o "estado de sítio" instalado no país.

O repúdio ao combate à produção de coca se fortaleceu no governo de Hugo Banzer Suárez (eleito em 1997), quando a repressão transformou-se em "guerra" pela erradicação (Bolivia..., 1998). Entre os insurgentes que, na segunda metade de 2000, bloqueavam estradas e lutavam contra as forças de segurança, em Cochabamba e Oruro, figuravam plantadores de coca exigindo a preservação de espaços para cultivo no Chapare, a nordeste de Cochabamba, e o fim das iniciativas de extinção em Yungas, ao norte de La Paz. À frente da sublevação perfilavam-se Evo Morales e Felipe Quispe, este também uma liderança aimará, defensor do "nacionalismo indigenista" (pertencente ao Movimiento Indigenista Pachacutik).

Mas a questão da coca, perpassada por forte crítica ao envolvimento dos Estados Unidos na repressão, compunha leque mais amplo de fatores da mobilização, embora lutar pelo cultivo representasse também censura à globalização, já que o setor cocalero simbolizava sobrevivência e resistência cultural. O período assistiu igualmente à "guerra da água", travada no primeiro semestre de 2000 em Cochabamba contra a concessão do serviço de fornecimento de água potável a uma empresa estrangeira - a multinacional estadunidense Bechtel -, que operaria com o nome de Aguas del Tunari. Contudo, o que realmente impulsionava os confrontos era o tema da pobreza, pois as reformas não diminuíram a exclusão social, e sequer os crescentes investimentos externos, privilegiando os setores de petróleo e gás, geravam ganhos expressivos de emprego.

No bojo desse processo, floresceu na Bolívia "um movimento, mescla de esquerda rural e urbana, sindicalismo e etnia, capaz de articular um discurso antineoliberal e anti-imperialista e incorporar uma visão étnico-cultural andina que 
interpela outros setores empobrecidos e marginalizados da sociedade boliviana" (Stefanoni, 2003: 59-60). De 2000 em diante, o país viveu uma ebulição política constante ou, como prefere Burgos (2005), um "contrapoder permanente", evocando a ideia de uma condensação da consciência - e de uma reação à altura - sobre séculos de espoliação por parte dos colonizadores e seus descendentes.

A alta voltagem política transparece, por exemplo, no fato de Gonzales Sánchez de Lozada, eleito presidente em 2002, ter renunciado em 2003 no calor da "guerra do gás”, expressão que remete às lutas em torno do projeto de exportar gás natural pelo sistema portuário chileno (sendo o Chile um inimigo histórico da Bolívia desde 1879, quando a Guerra do Pacífico suprimiu a saída marítima desse país). Desde a aprovação de lei sobre hidrocarbonetos, em meados dos anos 1990, beneficiando empresas multinacionais, a questão do gás se apresentava muito sensível em termos políticos. As medidas anunciadas por Lozada desencadearam vigorosa oposição popular, com marchas em defesa da soberania nacional. El Alto, cidade contígua a La Paz com cerca de 900 mil habitantes, na maioria aimarás pobres, virou o epicentro do conflito: após decretação de greve geral, realizou-se em outubro de 2003 uma enorme e ruidosa marcha sobre La Paz; os acontecimentos saíram do controle e provocaram a renúncia do presidente. Pouco depois ressurgia a "guerra da água", no rechaço popular à privatização do serviço na área de La Paz e El Alto - a exploração fora concedida à empresa francesa Suez-Lyonnaise des Eaux, operando como Aguas de Illimani. Iniciado no final de 2004, o movimento para expulsar a empresa atingiu o seu intento no início de 2005 (Chávez, 2005).

Foi nesse caldo de insurgência que o partido de Evo Morales, Movimiento al Socialismo (MAS), ganhou expressão como nova liderança política, paralelamente à deterioração das representações político-partidárias tradicionais.

"Frente à desidentificação nacional neoliberal, o MAS emerge como um novo nacionalismo plebeu que resignifica a luta nacional como uma luta pela terra e pelo território, e põe num lugar destacado a defesa dos recursos naturais, cuja dinâmica dominou os enfrentamentos sociais na Bolívia desde 2000, desde a guerra da água até a guerra do gás. É, ao mesmo tempo, uma tentativa de articular uma multitude de sujeitos, organizações e movimentos sociais em que nenhum setor é portador de privilégios ontológicos na construção das novas identidades, pelo que as mesmas são resultado das lutas hegemônicas e articulatórias em curso" (Stefanoni, 2003: 66 - itálico no original).

Desse modo a posse do vice de Lozada, Carlos Mesa, para um mandatotampão ocorreu em atmosfera de movimentos sociais fortalecidos, tanto que os setores populares conseguiram impor agenda política contemplando, além de um referendo sobre a exportação de gás, uma nova lei sobre os hidrocarbonetos e a convocação de uma Assembleia Constituinte. Os impasses em torno desses compromissos - resultando em outra agenda, na qual se exigia, previamente à Assem- 
bléia Constituinte, um referendo sobre a autonomia dos departamentos e a eleição de governadores - fizeram o governo se deparar, em 2005, com intensas demonstrações populares sobre questões de petróleo e gás e com as demandas de autonomia do Departamento de Santa Cruz, secundado por Tarija. O cenário de bloqueios de estradas e acirramento dos conflitos, entre grupos pró-nacionalização do petróleo e o gás e grupos interessados em liberalizar a exploração, provocou a renúncia do próprio Carlos Mesa em junho de 2005. A administração ficou com o presidente da Corte Suprema, que definiu calendário eleitoral para, em dezembro daquele ano, escolher o novo Presidente da República e integrantes do Congresso, e conduziu o processo de convocação da Assembleia Constituinte e do referendo sobre autonomia departamental.

Nesse clima, Evo Morales, reconhecido por posições menos radicais do que as de Felipe Quispe e seu Movimiento Indigenista Pachacutik, logrou alcançar a vitória na eleição presidencial. Contribuiu para isso a sua inclinação para coalizões interétnicas e interclassistas, envolvendo acordos entre o movimento indigenista e demais segmentos da esquerda, uma conduta aparentemente escorada no entendimento de que só mediante composições seria possível chegar ao poder pela via democrática (Lipietz, 2006). Não foi por outro motivo que Evo Morales obteve votação considerável mesmo em Santa Cruz, reduto da mais forte oposição ao seu governo.

\section{AÇÕES E REAÇÕES NO NOVO GOVERNO}

Evo Morales adotou medidas de grande impacto nos planos externo e doméstico. Internacionalmente, reverberaram sobretudo as ações ligadas à nacionalização dos setores de petróleo e gás. No front interno as repercussões vincularam-se, além daqueles setores, à Assembleia Constituinte, ao referendo sobre autonomia departamental e à reforma agrária. A Assembleia Constituinte é pilar básico das pretendidas mudanças, ao lado da nacionalização dos hidrocarbonetos e da reforma agrária, e constitui demanda histórica do movimento indígena do Altiplano. $\mathrm{O}$ referendo sobre autonomia departamental é reivindicado sobretudo pela elite empresarial do Departamento de Santa Cruz, acompanhada pelas de Tarija, Pando e Beni, com divergências em nível nacional: é mais favoráveis à autonomia a população das áreas mais ricas e são esmagadoramente contrárias as comunidades indígenas altiplânicas.

Fortes tensões em torno da Assembleia Constituinte e do referendo, com explosões de violência, se acumularam desde o início. Sobre a Assembleia, o foco dos atritos era o sistema de votação da matéria constitucional. A Lei de Convocatória definiu que $2 / 3$ dos votos representariam o limite mínimo para aprovação. Como o governo não conseguiu número de constituintes que desobrigasse a negociação com os opositores, passou a reivindicar que, em vez de $2 / 3$, bastasse a maioria simples. Sobre o referendo da autonomia, os governadores (Prefectos) oposicionistas queriam 
a prevalência dos resultados de cada departamento: ter-se-ia mais autonomia onde o "sim" vencesse, respeitando-se as "vontades departamentais". Para o governo central deveria valer o resultado agregado, impondo-se a todos a "vontade nacional". Em quatro departamentos - Santa Cruz, Pando, Beni e Tarija, que se designam partes da chamada "meia-lua", com adjetivações exaltando a eficiência econômica e a prosperidade - ganhou o "sim", mas a recusa venceu nacionalmente.

Os oposicionistas cerraram fileiras em torno do sistema de votação, que passou a ser visto como problema ligado ao da autonomia. O resultado negativo, em termos nacionais, do referendo sobre a autonomia departamental fez as lideranças pró-autonomia considerarem que a votação por maioria simples poderia redundar na exclusão desse tema da pauta dos constituintes. Os meses após a instalação da Assembleia Constituinte registraram manifestações tanto nas zonas mais favoráveis à autonomia quanto no Altiplano. Em setembro de 2006 houve paralisações de atividades e bloqueios de estradas, acompanhados de confrontos e agressões, nos departamentos da "meia-lua", sobretudo em Santa Cruz. Talvez o paroxismo tenha ocorrido durante a Expocruz, a principal feira de negócios da Bolívia, realizada nesse departamento: em quatro décadas, a Expocruz de 2006 foi a primeira em que se deixou de convidar o presidente do país. A apresentação de projeto de reforma agrária prevendo assentamentos em áreas de grandes fazendeiros, e a aprovação pelos constituintes governistas do caráter "originário" da nova Carta, podendo mudar toda a legislação vigente, elevaram o tom dos embates.

Em novembro, outros movimentos fizeram recrudescer os conflitos. Um deles foi a apresentação ao Congresso de uma nova lei de terras, prevendo desapropriações só por medidas administrativas (sem possibilidade de recurso); em discordância, a oposição ausentou-se da respectiva sessão. Aprovado na Câmara dos Deputados, o projeto foi enviado ao Senado, com desdobramentos que evoluíram para uma crise política: em maioria, a oposição retirou a bancada do seu maior partido e travou o processo, uma atitude qualificada por Evo Morales de golpista. Esse projeto de lei tinha irrestrito apoio dos indígenas do Altiplano, e estes, perante as dificuldades do governo, promoveram marchas para Cochabamba e La Paz em defesa da aprovação, ao que produtores rurais e líderes empresariais responderam com manifestações em Cochabamba e Santa Cruz. Um outro movimento foi o envio ao Congresso de projeto de lei sobre a fiscalização dos governos departamentais pelo Poder Legislativo, prevendo censura capaz de obrigar os governadores à renúncia $\mathrm{e}$ a exclusividade da ação presidencial na decisão de manter os primeiros nos cargos. Mas o que mais exacerbou os conflitos foi o sucesso do governo na aprovação do sistema de maioria simples nas votações da Assembleia Constituinte, a despeito da Lei de Convocatória. Houve o brusco rompimento do diálogo dos governadores de Santa Cruz, La Paz, Beni, Cochabamba, Tarija e Pando com o governo central e o início de uma greve de fome por constituintes e militantes de oposição.

A situação deteriorou-se ainda mais com a convocação, no final de novembro, de ações de resistência civil por lideranças políticas de Santa Cruz, acompanhando 
o que políticos de oposição já realizavam em Sucre. Isso foi rapidamente seguido em Beni, Pando, La Paz, Oruro, Cochabamba e Tarija, indicando capacidade de articulação e mobilização oposicionista mesmo fora das áreas mais ricas. Mas também o governo demonstrou habilidade ao conseguir, por manobra política, a aprovação da nova lei de reforma agrária. Como o alvo desta eram as terras dos departamentos mais oposicionistas, a chance de arrefecimento das tensões era quase nula, como sugeriam o ultimato e as ameaças de paralisação geral das respectivas organizações cívicas (entre elas a influente Cámara Agropecuaria del Oriente $\mathrm{CAO}$, de Santa Cruz), com exigências de revisão das posições governamentais.

$\mathrm{Na}$ escalada dos confrontos, lideranças regionais fizeram em dezembro uma grande manifestação em Santa Cruz objetivando anunciar por conta própria uma maior autonomia em relação a La Paz, ou mesmo a "independência" dos departamentos da "meia-lua" (Oposição..., 2006b). O quanto isso repercutiu junto ao governo tomou forma na exortação de Evo Morales para que as forças armadas defendessem a integridade da nação em caso de necessidade. No marco de enfrentamentos entre opositores e simpatizantes do governo, no interior daquele departamento, o evento exibiu expressões de franca recusa das orientações da administração central. Santa Cruz abrigou a maior e mais concorrida mobilização, mas também Tarija, Pando e Beni realizaram simultâneas assembleias populares (ou cabildos, um termo herdado da colonização hispânica). No prolongamento dos atritos na capital e no interior de Santa Cruz, com o agravamento da crise política, as lideranças oposicionistas passaram a conclamar a população para que não reconhecesse a nova Constituição, e o governador de Santa Cruz ameaçou criar o princípio de um Estado de direito na sua jurisdição.

\section{CLASSE, ETNIA E TERRITÓRIO: TRÊS DIMENSÕES DOS CONFLITOS}

Não são poucas as arestas da infante experiência boliviana. As que opõem proprietários e trabalhadores são claras, a confrontação pela reforma agrária não significando outra coisa. Os embates possuem igualmente conteúdo étnico, sendo pleno de significado o projeto de lei para legalizar a "justiça comunitária" apresentado em janeiro de 2007: baseadas em normas próprias e tradicionais, as decisões das autoridades indígenas e camponesas seriam validadas e cumpridas obrigatoriamente nas comunidades. No mesmo diapasão étnico situou-se o presidente do Comitê Cívico de Santa Cruz ao salientar, em manifestação anti-Morales, que "o povo cruzenho não aceita que um só partido [...] pretenda a supremacia de uma só etnia ou de um só setor [...]" (Bolivia..., 2006: s/p).

Mas essas questões mostram-se entrelaçadas com as de natureza territorial, a ponto de ligar-se a esta a dimensão que mais se destaca nos conflitos. A imagem, de fato, é uma Bolívia cindida em duas partes: uma andina, mais pobre e com tradição indígena de origem inca, nacionalista e adversária do neoliberalismo; a outra 
vinculada às terras baixas, com dinamismo econômico e predomínio do discurso pela modernização e a competitividade. Na contestação de dezembro de 2006 observavam-se nas ruas de Santa Cruz de la Sierra slogans do tipo "faço parte de uma nova república" e, grafada ao lado do mapa da "meia-lua", a indicação de que este é o "meu país" (Maisonnave, 2006a).

Uma justaposição entre questões de classe e territoriais pôde ser notada no torvelinho motivado pelo projeto de reforma agrária. O bloqueio da oposição no Senado provocou a mobilização de grupos indígenas do Altiplano, ao que responderam produtores rurais e líderes empresariais do leste boliviano, as disputas entre despossuídos e proprietários, entre trabalhadores rurais e patrões, entretecendo-se com o confronto entre, grosso modo, a Bolívia andina e a Bolívia oriental. Observe-se que nas ações pró-reforma agrária intervêm elementos regionalistas que evocam a análise de Mariátegui (1979) sobre o "novo regionalismo" peruano das primeiras décadas do século XX: um regionalismo que, em vez de apenas protesto contra a centralização administrativa, era "uma expressão da consciência serrana e do sentimento andino" (p. 140).

Quanto à imbricação de questões étnicas e espaciais, cabe referir à análise do diretor da Fundação Terra, de La Paz (em entrevista a Maisonnave, 2006b: A14): enquanto no Altiplano ocorre "uma radicalização étnica por parte do primeiro governo indígena da história e, portanto, há um sentimento antielitista", em Santa Cruz e nos outros departamentos da "meia-lua" enraizou-se a noção "de que se trata de uma invasão de índios [promovida] por um presidente anticruzenho. Santa Cruz se sente vítima do país" (Ibid.). Esta representação transparece nas ações de entidades como o Movimiento Nacional Camba de Liberación, ou Nación Camba, ${ }^{2}$ que propugna a existência histórica de uma outra nação ao lado da Bolívia andina, esta mais conhecida internacionalmente e via de regra entendida como sinônimo de "bolivianidade": uma nação no oriente boliviano, com traços próprios em muitos sentidos (Mosqueira, 2003) e merecedora, segundo esse Movimiento, de "soberania plena sobre sua economia, seu território e sua cultura" (Quienes..., s/d: s/p).

A sensação de "vítima do país" incidiu especialmente em Tarija quando as lutas sobre a exploração e exportação de gás - capitaneadas pelos movimentos sociais do Altiplano - ameaçaram os planos de desenvolvimento das lideranças. Como assinalam Vacaflores e Lizárraga (2005), ao longo de décadas incrustou-se no imaginário local a ideia de que Tarija era desconsiderada nas iniciativas governamentais de promoção do desenvolvimento. Essa percepção teria modelado um "regionalismo tarijeno" que se manifestou fortemente na mobilização em torno do gás - cerca de $80 \%$ das reservas descobertas na Bolívia estão nesse departamento.

\footnotetext{
2 "Camba" designava originalmente indígenas, trabalhadores rurais e camponeses do leste boliviano, mas passou a indicar identidade regional, generalizando-se. A sua contraparte é "colla", usada para indígenas andinos, até os que migraram para o oriente, a maioria pobre e trabalhando para patrões "camba" em atividades de baixos salários.
} 
Assim, Tarija permitiria subscrever a postulação de que as lutas regionais costumam guardar relação com o perfil territorial das forças produtivas e com as mudanças em tal perfil (Roger, 1979).

Entretanto, assim como em Santa Cruz, procurou-se construir em Tarija o ideário de uma forte coesão interna sobre o desenvolvimento com base nos recursos naturais. Esse processo, tendo as elites políticas e empresariais como ponta de lança e os Comitês Cívicos como instrumentos básicos, implicou carimbar a Bolívia andina com o rótulo de adversária (quiçá inimiga). As figuras das "duas Bolívias" e da "meia-lua" têm papel de realce nessa estratégia, representando o deslocamento dos embates para o plano das relações inter-regionais e tentando evitar o tema das disputas internas sobre o excedente gerado localmente. O discurso que vocaliza essa construção joga com duas cartas principais. Uma é a da identidade - estratégica para "produzir" o grupo, “impondo-lhe princípios de visão e de divisão comuns, portanto, uma visão única da sua identidade, e uma visão idêntica da sua unidade" (Bourdieu, 2002: 117) -, exaltando a "nação camba" e, por contraste, apequenando os "colla". A outra é a da performance econômica, como verbalizado pelo presidente do Comitê Cívico de Santa Cruz: "há mais de quarenta anos carregamos nas costas a economia da Bolívia" (Oposição..., 2006a: A13).

Ora, não é verdade que inexistem conflitos internos, nos departamentos orientais ou nos ocidentais. Qualquer ilusão se dissipa quando se consideram as históricas e profundas desigualdades sociais existentes no país. A rigor, a consciência dos excluídos dos frutos do progresso econômico nos departamentos mais ricos só faz crescer, encorpando os embates com a classe dominante local sobre as iniciativas dos Comitês Cívicos e sobre o uso das receitas da exploração dos recursos naturais. Mobilizações e choques não estão ausentes desses antagonismos, nos quais marca igualmente presença um "nacionalismo popular" contraposto à orientação pró-mercado dos estratos dominantes. Num certo sentido, portanto, tais departamentos são microcosmos da totalidade boliviana. "No nível regional os conflitos disputam o controle sobre o excedente, e através de seus conceitos questionam o modelo de desenvolvimento, coincidentemente com os movimentos sociais em nível nacional" (Vacaflores e Lizárraga, 2005: 31). Há conflitos de interesses mesmo entre indígenas: no turbilhão dos eventos recentes, "representantes das três principais etnias indígenas dos departamentos [...] [orientais] divulgaram uma nota pedindo a separação do país. Para os indígenas guarayos, guaranis e chiquitanos, 'chegou o momento de se levar adiante o processo de separação da Bolívia andina para dar lugar ao nascimento de uma pátria nova"” (Agricultores..., 2006: A20).

De todo modo, é fato que a dimensão territorial sobressai nesse cenário, reiterando a tese de que "a questão regional constitui uma constante na vida institucional da Bolívia" (Dunkerley, 2005: 14). Divisar os vetores do regionalismo no leste de um país onde esse tipo de movimento constitui um aspecto central do cotidiano é, assim, empreitada que merece o esforço da tentativa. 


\section{VETORES DO REGIONALISMO NO LESTE DA BOLÍVIA}

O terreno para se perscrutar o atual regionalismo boliviano é o histórico: a "finalidade da história, sua motivação profunda, não é a explicação da contemporaneidade?" (Braudel, 1998: 575). Mas como aqui a história se entremeia com a geografia, devido à natureza da questão específica, o campo que se impõe é o da geo-história. Para o que interessa ao artigo, este se refere a país incrustado em imenso território que por séculos pertenceu ao Império Espanhol e se tornou independente no começo do século XIX. Tem igualmente a ver com percurso republicano marcado por histórias regionais pouco articuladas entre si, algo ligado à forma de ocupação, às dificuldades impostas pelo meio físico, ao comportamento dos governos centrais e às trajetórias das estruturas produtivas territorializadas.

Esta frase de Mariátegui (1979: 11) sintetiza a motivação espanhola no povoamento das terras americanas, sugere o seu impacto e encaminha o entendimento do perfil socioespacial resultante: "[a] mineração - atividade fundamental do regime econômico implantado pela Espanha em território sobre o qual prosperou antes uma sociedade genuína e tipicamente agrária - exigiu que se estabelecessem na serra as bases da Colônia". A "sociedade genuína e tipicamente agrária" é a inca, cujo império foi derrotado pela Espanha na expansão territorial da economiamundo europeia no século XVI (Wallerstein, 1999). E a mineração dizia respeito à prata, crucial para as compras espanholas no Extremo Oriente e para as guerras do império. Em meados do século XVI, a América não era senão "uma boca de mina centrada, sobretudo, em Potosí” (Galeano, 1978: 34), uma condição mantida até o século XVIII. É significativa a criação, em 1550, de um Vice-Reino com sede em Lima (outrora Ciudad de los Reyes), fundada em 1535 por espanhóis.

Esse tipo de origem marcaria toda a vida colonial da área e modelaria o território, pois eram as necessidades do setor mineiro que organizavam o espaço. Essa atividade exigia produção de alimentos e ativava fluxos comerciais desdobrados em superfícies mais ou menos próximas às minas, as redes de vínculos do período inca sendo amplamente utilizadas nesse processo. Logo, apesar das evidências de que Potosí era nutrida por um "vasto sistema regional do qual participavam centros como Quito, Assunção, Tucumán, Buenos Aires e outros [...]” (Mitre, 1985:131), foi em torno do eixo Potosí-Lima, quer dizer, no Altiplano e nos vales, que o território se desenvolveu (Transformaciones..., 2003). O alastramento da ocupação refletiu as urgências administrativas e políticas do Estado espanhol e se subordinou aos interesses da mineiração, sem alterar substancialmente o padrão espacial de "uma série de pequenos e médios centros urbanos e mineiros em áreas de grandes alturas [...]" (García; Cordero; Izquierdo, 1987: 242). Pode-se dizer que, no essencial, esse padrão foi conservado após a independência, em 1825.

As relações do oriente boliviano com esse mundo andino-mineiro eram rarefeitas. Sua ocupação remonta às expedições espanholas em busca de metais preciosos 
no início do século XVI, realizadas a partir da exploração do Rio Paraná. ${ }^{3}$ Fundada em 1561, Santa Cruz de la Sierra tornou-se centro de apoio dessas iniciativas, além de suporte à contenção militar do avanço português. O século XVII seria marcado por expedições para a conquista de terras aos índios, a conversão destes ao catolicismo e o seu uso na agricultura. Missões jesuíticas foram iniciadas no final desse século e resultaram em instalações que até meados do século XVIII apresentaram intensas atividades. Essa história regional, que, como a da Bolívia andino-mineira, não é senão um aspecto da evolução do capitalismo mundial, cruzou-se pouco com a história da Bolívia ocidental. As distâncias e as dificuldades de comunicação e transporte, somadas ao peso da mineiração na estrutura social e produtiva do país, com o poder nacional sempre concentrado na oligarquia mineira, encontram-se entre as principais razões, que por extensão subjazem à débil coesão interna da Bolívia.

Assinale-se que as carências nas comunicações prolongaram-se após a independência, atravessaram o século XIX e perduraram. Isso ensejou movimentos regionais em Santa Cruz desde a virada para o século XX, o contexto dos quais incluía os obstáculos enfrentados pelos produtores locais para alcançar mercados na região andina, determinando uma situação agravada pela concorrência estrangeira que se intensificou com a política liberalizante do governo central para favorecer a mineração. Grupos do oriente boliviano multiplicaram as reivindicações por investimentos, o que se traduziu em comités pro-ferrocarril e na inclusão de luchas por el ferrocarril em programas de partidos políticos (Ostria, 1987).

Assim, embora a independência criasse um Estado autônomo, circunscrevendo o antigo Alto Peru com fronteiras nacionais, o caráter fortemente centralizado dos sucessivos governos foi sempre confrontado por uma difícil unidade nacional (Dozer, 1966). Sinônimo de grande instabilidade política, esse problema perpassou o período de dominação caudilhesca no século XIX e se prolongou.

Na década de 1950 a mineração, agora centrada no estanho, permanecia como setor básico. Todavia o oriente não mais se mostrava um protagonista secundário. O problema das comunicações fora enfrentado com a rodovia Cochabamba-Santa Cruz, concluída em 1954: "pela primeira vez na história boliviana as terras agricultáveis potencialmente produtoras de excedentes nas terras baixas foram conectadas com os centros populacionais do Altiplano por transporte motorizado durante todo o ano" (Encyclopedia..., 1963: 879). Ao mesmo tempo, a reforma agrária feita pela Revolução de 1952 - com a chegada ao poder do Movimiento Nacionalista Revolucionário (MNR), que buscava ainda a nacionalização das minas de estanho e a melhoria nas condições dos trabalhadores - estimulava migrações desde o Altiplano para as terras baixas, onde os proprietários mantiveram as grandes dimensões de suas glebas e, com auxílio até estrangeiro (dos Estados Unidos), além da simpatia dos governos militares após a queda do MNR, desenvolveram uma agricultura comercial de grande escala (Gill, 1985). Portanto, se durante a primeira metade do século XX o crescimento de Santa Cruz foi ínfimo, nas últimas décadas a trajetória

\footnotetext{
${ }^{3}$ Esses aspectos da história do oriente boliviano foram extraídos de Mosquera (2003).
} 
é notável. Os hidrocarbonetos, fontes de riqueza para os departamentos envolvidos (Santa Cruz, Tarija) e largamente explorados por empresas transnacionais cujos interesses se confundem com os das elites regionais, tonificaram ainda mais as estruturas econômicas e contribuíram decisivamente para o desempenho observado.

Daí que as atuais iniciativas pela autonomia do oriente boliviano devem ser vistas em perspectiva. São resultado da combinação entre o prolongado "distanciamento" dos principais processos políticos e econômicos nacionais e um crescimento econômico baseado em recursos regionais, no marco de tênues interações com o resto do país. A grande presença de capitais estrangeiros nos setores-chave certamente contribuiu, mostrando-se a Bolívia ilustrativa de um marcante traço da América Latina no século XX: a presença do capital transnacional frequentemente rimou com desintegração nacional (Sunkel, 1973). Adicionando-se ao quadro as particularidades culturais e a força adquirida por uma "elite de patrões" (Serrate, 2005), muitos destes com vínculos internacionais, o resultado é um sentido de defesa e busca de autonomia que Pittari (1989) haveria de incluir no "novo regionalismo" boliviano das últimas décadas. O ambiente assim criado funcionou como cadinho para ebulições autonomistas quando os movimentos sociais do Altiplano foram às ruas e deflagraram violentas manifestações pela nacionalização do setor de hidrocarbonetos, e quando o governo Morales implementou medidas vistas como ameaçadoras aos interesses econômicos regionais.

Mas também as frustrações com a descentralização administrativa e política no país não são estranhas ao fervilhar autonomista atual. Segundo Roca (2005), o século XX assistiu a pelo menos duas grandes tentativas nesse sentido: uma em 1931, quando um referendo encaminhou a descentralização em reforma constitucional, depois suprimida; a outra em 1993, com a Lei de Descentralização, desvirtuada por Lei de Participação Popular prevendo a transferência de fundos nacionais para os municípios sem a outorga de funções governamentais. Depois veio a Lei de Descentralização Administrativa, atribuindo o poder executivo departamental a Prefectos (nomeados e demitidos pelo Presidente, algo depois alterado com a introdução de eleições) e a Consejos Departamentales. O descaso com a descentralização teve consequências a partir dos conflitos de outubro de 2003, já que as posições se radicalizaram com as exigências cruzenhas de autonomia departamental. "Isso [...] desencadeou uma reedição da pugna regional, agora polarizada entre Santa Cruz, cabeça do Oriente, e La Paz [...], convertida em cidade insígnia da macrorregião andina já conhecida como 'Ocidente'” (Roca, 2005: 274)

\section{CONSIDERAÇÕES FINAIS}

A Bolívia registra excitação política com ingredientes étnicos e um forte papel de forças "nacional-populares". O sucesso eleitoral de Evo Morales é indissociável dessa escalada, ela mesma incompreensível se desvinculada da crise dos partidos tradicionais e das reformas neoliberais dos anos 1980 e 1990. Embalado por vaga contestatória, o novo governo adotou medidas de grande repercussão, as quais, 
incidentes em país onde a frágil coesão socioespacial retrata as dificuldades impostas por configurações econômicas e políticas sempre desafiadoras da uniformização das aspirações e iniciativas, além de refletir o peso de interesses estrangeiros, desencadearam ou acentuaram embates com proeminente dimensão territorial.

$\mathrm{O}$ atual surto de clamores autonomistas no leste boliviano repousa nessa complexa articulação de fatores. Essas reivindicações podem ser interpretadas como respostas à ascensão de um indigenismo andino - impondo demandas e tentando fazer valer direitos - que Quijano (1992: 76) haveria de associar ao que vê como um "processo de reoriginalização da América, com [...] implicações sobre o poder, a sociedade e a cultura". Ao mesmo tempo, ressoam o estreitamento dos vínculos entre instâncias regionais e a economia mundial, na esteira dos investimentos externos para o setor de hidrocarbonetos e da descoberta de imensas reservas de gás, um processo em que "as fronteiras entre Estado e mercado e entre o central e o local no interior do Estado [sofreram mudanças, representando base sobre a qual] se começou a reconfigurar a geografia nacional [...]" (Transformaciones..., 2003: 11). Essa condição do oriente boliviano tonificou os movimentos conduzidos pelas lideranças regionais na áspera interlocução com o governo Morales e na polarização com os movimentos sociais altiplânicos, cevando discursos e práticas que às vezes entremostram inquietantes desejos secessionistas.

\section{REFERÊNCIAS}

AGRICULTORES tomam como refém governador de La Paz (2006). Folha de S. Paulo, p. A20, 7 dez.

BADER, C.; RODRIGO, J-M. (1994). L'avenir en noir et blanc de la Bolivie. Le Monde Diplomatique, p. 22-23, Mars.

BOLIVIA goes to war against coca (1998). The Economist, p. 43-44, Sep. $19^{\text {th }}$.

BOLIVIA: un millón de personas en manifestación por autonomía (2006). Foroperu, 19 Dic. Disp.: www.foroperu.com/ Aces.: dec. 2006.

BOURDIEU, P. (2002). A identidade e a representação: elementos para uma reflexão crítica sobre a ideia de região. In: O poder simbólico. $5^{\text {a }}$ ed., Rio de Janeiro: Bertrand Brasil, p. 107-132.

BRAUDEL, F. (1998). Civilização material, economia e capitalismo: séculos XV-XVIII. $2^{\text {a }}$ ed. V. 3 - O tempo do mundo. São Paulo: Martins Fontes.

BURGOS, E. (2005). Bolivia o la pasión nacional. Nuevo Mundo Mundos Nuevos, ${ }^{\circ}$ 5, Jan. Disp.: http://nuevomundo.revues.org/document35.html. Aces.: nov. 2006.

CHÁvEZ, W. (2005). Effervescence populaire en Bolivie. Le Monde Diplomatique, p. 11, Mars.

DOZER, D. M. (1966). América Latina: uma perspectiva histórica. Porto Alegre: Editora Globo; Editora da Universidade de São Paulo.

DUNKERLEY, J. (2005). Prólogo. In: BARRAGÁN, R.; ROCA, J. L. Regiones y poder constituyente en Bolivia: una historia de pactos y disputas. Cuaderno de Futuro, La Paz, n. 21, p. 11-15, nov.

ENCYCLOPEDIA Británica (1963). V. 3. Chicago: William Benton. Bolivia, p. 874-886.

ESTADÍSTICAS Departamentales/Boletines Departamentales (2006). Instituto Nacional de Estadística. La Paz. Disp.: www.ine.gov.bo/cgi-bin/Depto_2004.exe/act. Aces.: dez. 2006.

GALEANO, E. (1978). As veias abertas da América Latina. $3^{\mathrm{a}}$ ed. Rio de Janeiro: Paz e Terra.

GARCIAA, R.; CORDERO, F.; IZQUIERDO, A. (1987). Economía y geografía del desarrollo en América Latina. México D.F.: Fondo de Cultura Económica.

GILL, L. (1985). La reforma agraria y el desarrollo del capitalismo en Santa Cruz, Bolivia (19521980). Historia Boliviana, Cochabamba, v. 1-2, p. 67-85. 
HUMAN Development Report 2005 (2005). Disp.: www.hdr.undp.org/reports/gloval/2005 Aces.: dez. 2006.

ÍNDICE de Desarrollo Humano en los Municípios de Bolívia/PNUD (2004). La Paz: PNUD, mar.

LEMOINE, M. (1995). Coca répression chez les payans boliviens. Le Monde Diplomatique, p. 22-23, oct.

LIPIETZ, A. (2004). La Bolivie entre Kollasuyu et Bolivarisme. Politis, n. 783, 8 jan. Disp.: //lipietz.net Aces.: nov. 2006.

LIPIETZ, A. (2006). L'Amérique du sud au carrefour. Mouvements, n. 47-48, aut. Disp.: //lipietz.net Aces.: nov. 2006.

MAISONNAVE, F. (2006a). Oposição e governistas se agridem na Bolívia. Folha de S. Paulo, p. A15, $16 \mathrm{dez}$.

MAISONNAVE, F. (2006b). Sojicultores brasileiros não serão atingidos. Folha de S. Paulo, p. A14, 30 nov.

MARKUSEN, A. R. (1981). Região e regionalismo: um enfoque marxista. Espaço \& Debates, ano 1, $\mathrm{n}^{\circ} 2$, p. 61-99, maio.

MARIÁTEGUI, J. C. (1979). 7 ensayos de interpretación de la realidad peruana. Caracas: Ayacucho.

MIGNOLO, W. D. (2006). Evo Morales en Bolívia. Revista del Sur, n. 164, Mar./Abr. Disp.: www.redtercermundo.org.uy Aces.: out. 2006.

MITRE, A. (1985). Espaço regional andino e política no século XIX. In: SORJ, B.; CARDOSO, F. H.; FONT, M. (orgs.). Economia e movimentos sociais na América Latina. São Paulo: Brasiliense, p. 131-144.

MOSQUERA, G. P. (2003). La Nación Camba: fundamentos y desafios. Santa Cruz de la Sierra: Nación Camba. Disp.:www.nacioncamba.net Aces.: set. 2006.

OPOSIÇÃO pára região mais rica da Bolívia (2006a). Folha de S. Paulo, p. A13, 9 set.

OPOSIÇÃO boliviana ameaça declarar independência (2006b). Folha de S. Paulo, p. A17, 12 dez.

OSTRIA, G. R. (1987). Mercado interior y conflictos regionales: Santa Cruz, 1891-1952. Historia Boliviana, v. 7, n $1-2$, p. 69-84.

PINTO,W. R. (2006). Pueblos indígenas de Bolivia. Disp.: www.amazonia.bo/pueblos.php Aces.: dez. 2006.

PITTARI, S. R. (1989). El nuevo regionalismo. Instituto de Investigaciones Sócio Econômicas. Documento de Trabajo $n^{\circ} 02 / 89$, feb.

QUIENES somos? (s/d). Nación Camba, Santa Cruz de la Sierra: Nación Camba. Disp.:www.nacioncamba.net Aces.: set. 2006.

QUIJANO, A. (1992). Notas sobre a questão da identidade e nação no Peru. Estudos Avançados, v. 6, $\mathrm{n}^{\circ} 16$, p. $73-80$.

ROCA, J. L. (2005). Estatalidad: entre la pugna regional y el institucionalismo. In: BARRAGÁN, R.; ROCA, J. L. Regiones y poder constituyente en Bolivia: una historia de pactos y disputas. Cuaderno de Futuro, La Paz, no 21, p. 17-274, nov.

ROGER, J-L. (1979). Régions, luttes de classes, profil des forces productives. La Pensée, $\mathrm{n}^{\circ}$ 207, p. 44-55, sep.-oct.

SERRATE, S. (2005). Bolivia: los desvelos de las elites. A-Infos, 1 feb. Disp.: www.ainfos.ca Aces.: nov. 2006.

STEFANONI, P. (2003). MAS-IPSP: la emergencia del nacionalismo plebeyo. OSAL, $\mathrm{n}^{\circ}$ 12, p.57-68.

SUNKEL, O. (1973). Transnational capitalism and national desintegration in Latin América. Social and Economic Studies, ${ }^{\circ}$ 22, p. 132-176.

TRANSFORMACIONES regionales en Bolivia (2003). La Paz: PNUD, Dic.

VACAFLORES R., C.; LIZÁRRAGA A., P. (2005). La lucha por el excedente del gas y la resignificación de las contradicciones de la identidad regional en Bolivia. OSAL, $\mathrm{n}^{\circ}$ 17, p. 21-31.

WALLERSTEIN, I. (1999). El moderno sistema mundial: la agricultura capitalista y los orígenes de la economía-mundo europea en el siglo XVI. $9^{a}$ ed. México D.F.: Siglo Veintiuno Editores.

WORLD Development Indicators-2006 (2006). The World Bank. Disp.: www.devdata.worldbank.org Aces.: dez. 2006.

ZAVALETA M., R. (1986). Lo nacional-popular en Bolivia. México: Siglo Veintiuno. 